\title{
STUDIES ON ANTIBIOTICS PRODUCED FROM KITASATOA KAUAIENSIS SP. NOV.
}

\author{
Kiminiko Abe and Toju Hata \\ The Kitasato Institute, Tokyo, Japan \\ (Received for publication July 17,1968 )
}

\begin{abstract}
Kitasatoa kauaiensis, a new species of the genus Kitasatoa, belonging to the family Streptoplanaceae, produces 3 kinds of antibiotics in a culture broth. These antibiotics were identified as chloramphenicol, bottromycin and fradicin based on their physico-chemical and biological properties. A new differential bioassay method for chloramphenicol and bottromycin produced in the same culture broth was established.
\end{abstract}

A strain of microorganism No. I-337, which was isolated from a soil sample in Kauai Isle of Hawaii Islands, differs from the genus Streptomyces in morphological findings. This new species belonging to a new genus Kitasatoa in the family Actinoplanaceae was named Kitasatoa kauaiensis, as reported in the separate paper ${ }^{1)}$. This strain was found to produce three kinds of antibiotics in the culture broth by a paper chromatography. Two antibiotics, I-337 A and B possess antibacterial activities against $B$. subtilis PCI 219, and the other antibiotic, I-337 C possesses antifungal activity against Saccharomyces cerevisiae.

The authors extracted three effective substances from a culture filtrate of the strain. On investigating physico-chemical and biological properties of these antibiotics, I-337 A was identified as chloramphenicol, B as bottromycin ${ }^{2)}$, and $\mathrm{C}$ as fradicin ${ }^{3,4)}$ respectively.

When No. I-337 strain is inoculated, I-337 A is often produced with B in the same culture broth. It became necessary to estimate both antibiotics I-337 A and B separately in the same culture filtrate for the purpose of increasing the amount of I-337 B. I-337 A showed a high activity to both Gram-positive and Gram-negative bacteria, while I-337 B showed an activity only to the Gram-positive bacteria and indicated a clear inhibition zone of $B$. subtilis at $\mathrm{pH}$. A new differential bioassay method was established using $E$. coli as test organism for I-337 A and B. subtilis for I-337 B. Present paper deals with extraction and isolation of I-337 A, B and C and with a differential assay method of chloramphenicol and bottromycin in the same culture broth.

\section{Materials and Methods}

(1) Fermentation

The antibiotic-producing strain, No. I-337, was maintained on WAKSMAN's or KRAINSKY's agar slants. The inoculum for a jar fermentor was incubated for 48 hours at $27^{\circ} \mathrm{C}$ on a reciprocal shaker. 
A seed $(0.5 \%)$ was inoculated into 20 liters of culture medium in a 30-liter stainlesssteel jar fermentor and the fermentation was carried out at the following conditions: temperature, $28^{\circ} \mathrm{C}$; aeration 20 liters $/ \mathrm{min}$.; agitation, $230 \mathrm{rpm}$; and pressure, $0.5 \mathrm{~kg} / \mathrm{cm}^{2}$.

Samples were obtained at 12 -hour intervals to observe $\mathrm{pH}$, mycelial volume, carbohydrate utilization and antibacterial activity.

(2) Estimation of Antibacterial Activities of Antibiotics.

The antibacterial activity of $\mathrm{I}-337 \mathrm{~A}$ and $\mathrm{B}$ was estimated by a paper disc plate metod using E. coli grown on nutrient agar at $\mathrm{pH} 7$ and $B$. subtilis PCI 219 grown on nutrient agar at $\mathrm{pH} 8$, respectively.

Agar plates for the paper disc method were prepared as follows: Ten $\mathrm{ml}$ of nutrient agar medium for base layer and $4 \mathrm{ml}$ of seed agar medium for seed layer were dispensed into each Petri dish.

(3) Paper Chromatography.

Paper chromatography of the broth filtrate was carried out on Tōyōroshi No. 50 paper strips $(1 \times 40 \mathrm{~cm})$ by the ascending methods with $3 \%$ ammonium chloride solution. The dried strips were bioautographed against $B$. subtilis PCI 219 on agar medium ( $\mathrm{pH} 8$ ). The $\mathrm{Rf}$ values of $\mathrm{I}-337 \mathrm{~A}$ and $\mathrm{B}$ were approximately 0.78 and 0.56 respectively.

\section{Experimental Results}

\section{Isolation and Purification of I-337 A}

A 20 -liter batch of the broth was filtered and the filtrate was extracted successively with 6-liter and 4-liter portions of ethyl acetate. The extract was concentrated to dryness in vacuo and crude substance $(2.5 \mathrm{~g})$ obtained was dissolved in a minimal volume of acetone and purified by chromatography on a colum $(2.8 \times 15 \mathrm{~cm})$ containing $100 \mathrm{~g}$ of aluminum oxide. The active fraction was eluted with $30 \%$ methanol in chloroform and dried in vacuo. I-337 A (750 mg) was obtained as colorless needle crystals with acetone-chloroform and overall yield was $24 \%$.

\section{Isolation and Purification of $\mathrm{I}-337 \mathrm{~B}$ and $\mathrm{C}$}

I-337 $B$ and $G$ were extracted from the fermentation broth in a 400-liter stainlesssteel fermentor. The fermentation broth, fermented in the soybean meal medium for 3 days was filtrated and the filtrate (360 liters) was extracted two times with 80liter and 40-liter portions of ethyl acetate at $\mathrm{pH} 7.2$. The extract (80 liters) was concentrated to 17 liters and extracted four times with $0.1 \mathrm{M}$ acetic acid solution (3.4 liters). Acetic acid phase (14.5 liters) was neutralized with $3 \mathrm{~N}$ sodium hydroxide and again extracted three times with ethyl acetate ( 3 liters) at $\mathrm{pH} 7.8$. The extract was dried in vacuo to obtain a crude powder (5.9 g) containing I-337 B and $\mathrm{C}$. The product thus obtained was purified by alumina column chromatography $(120 \mathrm{~g}$ of aluminum oxide, column $2.5 \times 15 \mathrm{~cm}$ ) with chloroform as a developer. The active fraction ( $1.8 \mathrm{~g}$ ) containing $\mathrm{I}-337 \mathrm{~B}$ and $\mathrm{C}$ was dried in vacuo. The active fraction was further purified by Sephadex LH20 column chromatography using methanol as a developer. I-337 B was eluted first, subsequently I-337 C. Each fraction was combined and concentrated in vacuo. I-337 B ( $1.5 \mathrm{~g})$ was obtained as a white amorphous powder with overall yield $60 \%$. I-337 C (30 mg) was obtained as pale yellow needles from chloroform-methanol.

\section{Identification of the Antibiotics}

I-337 A was obtained as colorless needles with a melting point of $148 \sim 149^{\circ} \mathrm{C}$ by 
Fig. 1. Two-dimensional cellulose thin-layer chromatogram of I-337 B hydrolysate ( $6 \mathrm{~N} \mathrm{HCl}$, for 24 hours).

Detected by ninhydrin.

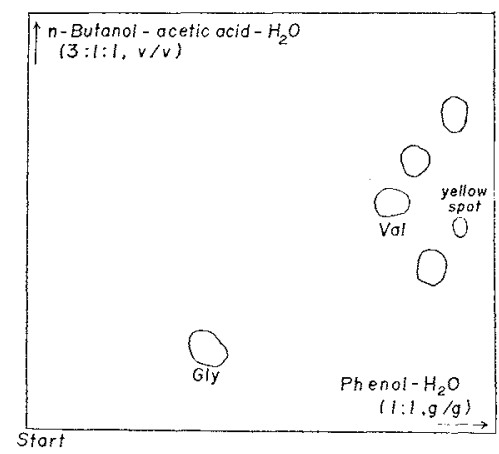

Fig. 2. Mass spectrum of I-337 B.

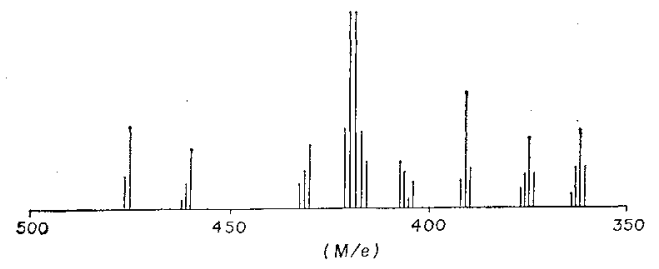

recrystallization. The ultraviolet absorption spectrum in methanol exhibits a maximum at $278 \mathrm{~m} \mu\left(\mathrm{E}_{\mathrm{iem}}^{1 \%}\right.$ 350). The following elementary analysis was obtained: $\mathrm{C} 40.95, \mathrm{H}$ 3.67, $\mathrm{N}$ 8.61. The antibiotic I-337 A was identified as chloramphenicol by the comparison of its infrared absorption spectrum and thinlayer chromatogram with those of the authentic sample of chloramphenicol.

I-337 B was a white amorphous powder with weak basic properties. The elementary analysis was as follows: C $60.89, \mathrm{H}$ $7.58, \mathrm{~N} 12.59, \mathrm{~S} 4.18$. The antibiotic had a specific rotation $[\alpha]_{D}^{25}-32.1^{\circ}$ (c 2 , methanol). The potentiometric titration of I-337 B in methanol-water showed one titrable group, $\mathrm{pK}^{\prime} \mathrm{a}$ 7.01. The equivalent weight based on the titration was 715 . The ultraviolet absorption spectrum of I-

$337 \mathrm{~B}$ in methanol showed an end absorption at $210 \mathrm{~m} \mu$. The presence of ester peptide bonds was indicated in the infrared absorption spectrum $\left(\nu_{\mathrm{C}=0}: 1745 \mathrm{~cm}^{-1}\right.$, $\mathrm{KBr}$ ). The nuclear magnetic resonance spectrum showed a peak at $\delta=3.7 \mathrm{ppm}$, corresponding to O-methyl group.

By hydrolysis of I-337 B with $6 \mathrm{~N}$ hydrochloric acid at $110^{\circ} \mathrm{C}$ for 24 hours, six ninhydrin-positive spots were detected in the hydrolysate by two-dimentional cellulose thin-layer chromatography with solvent systems consisting phenol-water $(3: \mathrm{I})$ and $n$-butanol-acetic acid-water $(3: 1: 1)$. The chromatogram thus obtained is indicated in Fig. 1. Two spots were confirmed to be glycine and valine by com-

Fig. 3, Infrared spectrum of $\mathrm{I}-337 \mathrm{C}(\mathrm{KBr})$.

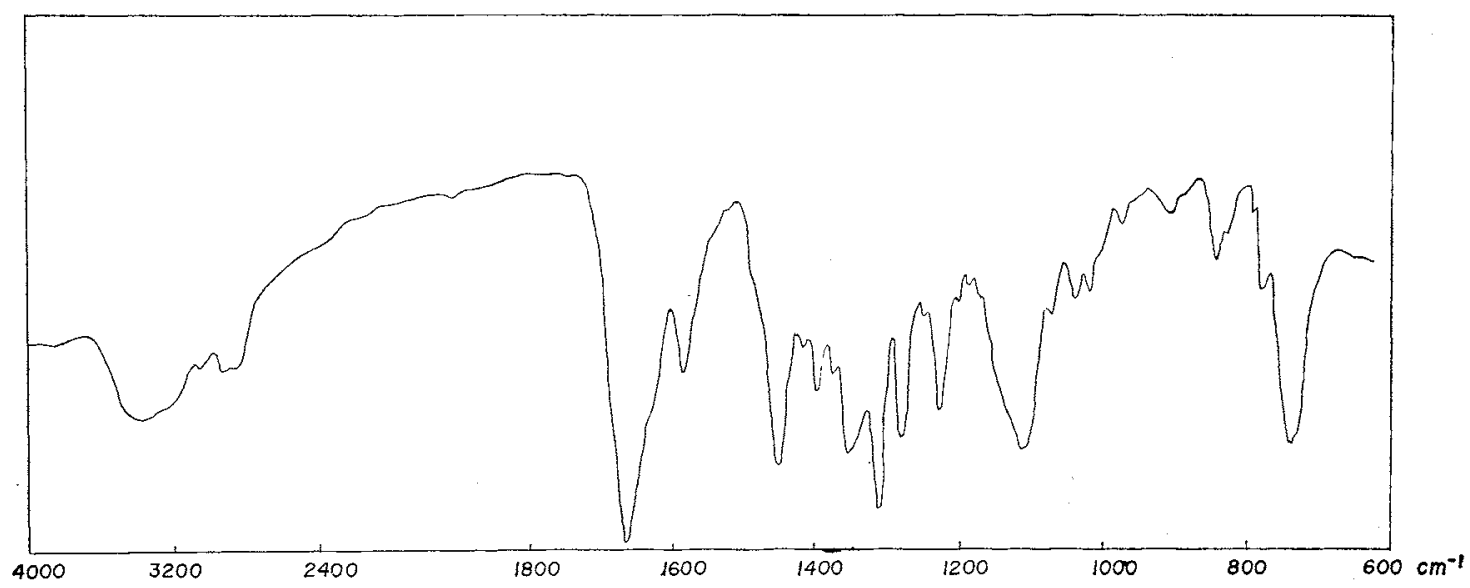


parison with their authentic samples, but others were not identified.

Based on the above facts, I-337 B was supposed to be identical with bottromycin.

When thin-layer chromatography using silica gel $G$ was carried out with the solvent system of $n$-butanol-acetic acid-water (100:12:100) (upper phase) and the developed plates were exposed to iodine vapour, two yellow bands were observed. The Rf value of the main band was approximately 0.7 , as same as that of an authentic sample of bottromycin $A_{2}$. The $R f$ value of the weak band was 0.65 . This seems to be bottromycin B. The main band was eluted with methanol and obtained as a white amorphous powder. The mass spectrum of this fraction showed a peak at $\mathrm{M} / \mathrm{e} 475$ (Fig. 2). This peak accords with the molecular weight of $A^{1}$-isocaproyltetrapeptide obtained from bottromycin $\mathrm{A}_{2}$ as reported by NAKAMURA et al. ${ }^{5,6)}$ From these data, I-337 $B$ was identified as bottromycin $A_{2}$ containing a trace of bottromycin $B$.

I-337 $\mathrm{G}$ was pale yellow needles and did not show a definite melting point. It was darkened slowly at above $200^{\circ} \mathrm{C}$. Analytical value was as follows: $\mathrm{C} 71.46, \mathrm{H}$ 5.59, N 11.67. I-337 $\mathrm{C}$ showed a characteristic ultraviolet absorption in methanol at $245\left(\mathrm{E}_{1 \mathrm{~cm}}^{1 \%} 660\right), 270(\mathrm{sh}), 295(1720), 325(\mathrm{sh}), 337(310), 356(170)$, and $375(250) \mathrm{m} \mu$. The infrared absorption spectrum of $\mathrm{I}-337 \mathrm{G}$ is shown in Fig. 3. I-337 $\mathrm{C}$ was identified as fradicin ${ }^{4}$ from the properties described above.

Differential Assay between I-337 A and B

Based on the isolation method described above, a differential assay between I-337 A (chloramphenicol) and B (bottromycin) was performed as follows: Ten $\mathrm{ml}$ of aqueous solution of purified sample of I-337 A or B was extracted with an equal volume of ethyl acetate and the ethyl acetate solution was reextracted with $10 \mathrm{ml}$ of $0.1 \mathrm{~m}$ acetic acid. The acetic acid phase was neutralized with $3 \mathrm{~N}$ sodium hydroxide. It was found by paper chromatography that I-337 A remained in the ethyl acetate

Table 1. Recovery tests

\begin{tabular}{|c|c|c|c|c|c|c|}
\hline \multicolumn{2}{|l|}{ Test sample } & $\begin{array}{c}\text { Acetic acid or } \\
\text { ethyl acetate } \\
\text { (ml) }\end{array}$ & $\begin{array}{l}\text { Potency } \\
(\mu \mathrm{g} / \mathrm{ml})\end{array}$ & $\begin{array}{l}\text { Total } \\
\text { potency } \\
(\mu \mathrm{g})\end{array}$ & $\begin{array}{c}\text { Total potency } \\
\text { minus } \\
\text { broth potency } \\
\text { ( } \mu \mathrm{g})\end{array}$ & $\begin{array}{c}\text { Recovery } \\
\text { ratio } \\
(\%)\end{array}$ \\
\hline Broth filtrate & $10 \mathrm{ml}$ & 11.4 & 10.8 & 123 & & \\
\hline $\begin{array}{l}\text { Broth filtrate } \\
\text { Bottromycin }\end{array}$ & $\begin{array}{r}10 \mathrm{ml} \\
200 \mu \mathrm{g}\end{array}$ & 11.2 & 26 & 296 & 173 & 87 \\
\hline$\prime \prime$ & $100 \mu \mathrm{g}$ & 11.4 & 18.2 & 207 & 84 & 84 \\
\hline$\prime \prime$ & $50 \mu \mathrm{g}$ & 11.4 & 14.8 & 169 & 46 & 92 \\
\hline $\begin{array}{l}\text { Distilled water } \\
\text { Bottromycin }\end{array}$ & $\begin{array}{r}10 \mathrm{ml} \\
200 \mu \mathrm{g}\end{array}$ & 11.0 & 16 & 176 & & 88 \\
\hline 11 & $100 \mu \mathrm{g}$ & 11.4 & 7.6 & 87 & & 87 \\
\hline$" \prime$ & $50 \mu \mathrm{g}$ & 11.4 & 3.7 & 42 & & 84 \\
\hline Broth filtrate & $10 \mathrm{ml}$ & 8.5 & 16.5 & 140 & & \\
\hline $\begin{array}{l}\text { Broth filtrate } \\
\text { Chloramphenicol }\end{array}$ & $\begin{array}{r}10 \mathrm{ml} \\
500 \mu \mathrm{g}\end{array}$ & 8.4 & 73.5 & 615 & 475 & 95 \\
\hline " & $200 \mu \mathrm{g}$ & 8.6 & 38 & 327 & 187 & 94 \\
\hline $\begin{array}{l}\text { Distilled water } \\
\text { Chloramphenicol }\end{array}$ & $\begin{array}{r}10 \mathrm{ml} \\
500 \mu \mathrm{g}\end{array}$ & 8.4 & 60.7 & 510 & & 102 \\
\hline " & $200 \mu \mathrm{g}$ & 8.4 & 29.5 & 185 & & 92 \\
\hline
\end{tabular}


Fig. 4. Fermentation patterns.

(1) Cornsteep liquor medium.

Cornsteep liquor $2 \%$, Starch $2 \%$,

Yeast $0.3 \%, \mathrm{NaCl} 0.5 \%, \mathrm{CaCO}_{3} 0.3 \%$

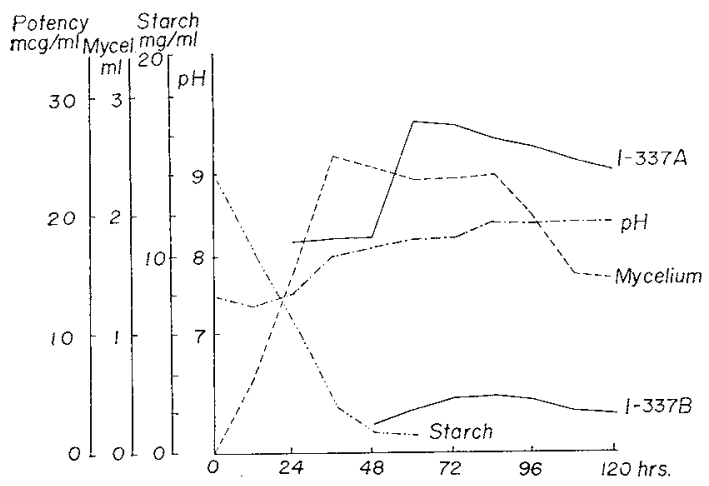

phase and I-337 B was transferred into dilute acetic acid. The antibacterial activity of the ethyl acetate phase (I337 A) was estimated by a paper disc method against $E$. coli grown on nutrient agar at $\mathrm{pH}$ 7. The doseresponse standard curve was prepared over the range of $6.25 \sim 100 \mu \mathrm{g}$ per $\mathrm{ml}$.

I-337 B was transferred into $0.1 \mathrm{M}$ acetic acid phase and the activity was estimated using $B$. subtilis PCI 219 grown on nutrient agar at $\mathrm{pH} 8$ as a test organism. The diameters of the clear inhibion zones were measured to prepare the standard curve. The standard curve was linear over the range of $1.6 \sim 100 \mu \mathrm{g}$ per $\mathrm{ml}$.

The fermentation broths could be assayed in similar fashion.

Recovery tests of I-337 A and B in the culture filtrate were performed by adding 500 , or $200 \mu \mathrm{g}$ of $\mathrm{I}-337 \mathrm{~A}$, and 200,100 or $50 \mu \mathrm{g}$ of $\mathrm{I}-337 \mathrm{~B}$ to $100-\mathrm{ml}$ portion of the broth filtrate or distilled water and assayed. The results are summarized in Table 1. The recovery of I-337 A was more than $90 \%$ and that of I-337 B $84 \sim 92 \%$.

A factor of 1.13 was used to correct the values of $\mathrm{I}-337 \mathrm{~B}$ for the recovery found.

\section{Fermentation Studies}

The time course of the fermentation of I-337 A and B is summarized in Fig. 4.

With a medium containing soybean meal, the highest production of I-337 A and B was obtained after 60 84 hours of fermentation, and the potencies of I-337 A and $B$ were on an average of $15 \sim 30 \mu \mathrm{g}$ and $10 \sim 20 \mu \mathrm{g}$ per $\mathrm{ml}$, respectively.

With cornsteep liquor as a nitrogen source instead of soybean meal, the maximal yields of $\mathrm{I}-337 \mathrm{~A}$ and $\mathrm{B}$ were 28.0 and $5.2 \mu \mathrm{g}$ per $\mathrm{ml}$ after $60 \sim 72$ hours, respectively.

When the fermentation was performed with a medium containing peptone, I-337 
A was the main product and no I-337 B was produced. A peak potency of $250 \mathrm{ug}$ per $\mathrm{ml}$ was obtained at 72 hours.

The data seem to indicate that the production of I-337 A and B may be much more dependent on the nitrogen sources, than on the carbohydrates in the medium. The peptone medium was favorable for the production of I-337 A and the soybean meal medium for the production of I-337 B.

\section{Acknowledgement}

The authors express many thanks to Dr. S. ŌmuRA of the Kitasato Institute and to Mr. A. NAKAGAWA of Kitasato University for their kind collaboration. They are also indebted to $S$. NAKAMURa for the kind supply of bottromycin $A_{2}$.

\section{References}

1) Matsumae, A.; M. Ohtani, H. Takeshima \& T. Hata: A genus of the Actinomycetales, Kitasatoa gen. nov. J. Antibiotics (in press).

2) Nakamura, S.; T. Chikaike, K. Karasawa, N. Tanaka, H. Yonehara \& H. Umezawa: Isolation and characterization of bottromycins A and B. J. Antibiotics, Ser. A 18:47 52, 1965.

3) SWart, E. A.; A. H. Romano \& S. A. Waksman: Fradicin, an antifungal agent produced by Streptomyces fradiae. Proc. Soc. Exp. Biol. Med. 73:376 378, 1950.

4) Hickey, R. J. \& P. H. Hrdy: Crystalline fradicin. Science 113 (2935) : 361 362, 1951.

5) Nakamura, S.; N. Tanaka \& H. UmeZaWa: Bottromycin $A_{1}, A_{2}$ and their structures. J. Antibiotics, Ser. A $19: 10 \sim 12,1966$.

6) NAKAMURA, S.; T. YAJima, Y. LiN \& H. UMEZAWA: Isolation and characterization of bottromycin $A_{2}, B_{2}, C_{2}$. J. Antibiotics, Ser. A $20: 1 \sim 5,1967$. 